\title{
Discussion on the Improvement of Technical Safety Scheme Compilation for Hazardous and Ultrahazardous Projects
}

\author{
Yi Gong*, Bingyang Yang \\ China First Metallurgical Group Co., Ltd., China \\ *Corresponding author: Yi Gong, 278974045@qq.com
}

Copyright: () 2022 Author(s). This is an open-access article distributed under the terms of the Creative Commons Attribution License (CC BY 4.0), permitting distribution and reproduction in any medium, provided the original work is cited.

\begin{abstract}
This paper reviews the summary and analysis of special technical safety schemes for hazardous and ultrahazardous activities, supported by housing scaffolding, installation, and dismantling of outer wall attached tower crane, deep foundation pit with supporting structure, municipal bridge box girder formwork support, as well as grooved Larsen steel sheet pile, which are commonly seen in recent years, so as to enhance the pertinence, rationality, and economy of the special program to strengthen safety.
\end{abstract}

Keywords: Hazardous and ultrahazardous; Scheme; Compilation; Improvement

Online publication: January 12, 2022

\section{Introduction}

China's gross domestic product (GDP) increased by nearly eighty times, from US \$1,958.66 billion in 1981 to US $\$ 15.69$ trillion in 2020 . The construction industry has also developed rapidly. Especially in the past decade, due to industrial transformation, market expansion, and new business growth, safety management has been heavily emphasized. The construction industry is a high-risk industry. In order to protect people's lives and property safety, the state has issued a series of laws and regulations to give clear definitions and technical management requirements for hazardous and ultrahazardous activities in construction projects. From document No. 87 of the General Office of the Ministry of Housing and Urban-Rural Development (2009) to order No. 37 of the Ministry of Housing and Urban-Rural Development (2018), order No. 393 of the State Council, order No. 279 of the State Council, document No. 31 of the General Office of the Ministry of Housing and Urban-Rural Development (2018), document No. 343 of the Office of the Department of Housing and Urban-Rural Development of Hubei Province (2018], and document No. 7 of Wuhan Urban and Rural Construction Bureau (2012), the state has revised the Security Law several times; the construction enterprise has also formulated and implemented a strict management system; the overall security situation has been effectively controlled. The flow of talents in construction enterprises is frequent, and the refinement deficiencies as well as contradictions in the preparation of special technical safety schemes for hazardous and ultrahazardous divisional and subdivisional projects are becoming more apparent. 


\section{Deficiency analysis and compilation improvement suggestions of special scheme for scaffold}

Scaffolding here mainly refers to the floor type and cantilever scaffold of civil buildings as well as falsework.

\subsection{Floor-type scaffold}

At present, the floor-type scaffold is mainly used in buildings with a height of less than 50 meters: low rise, small high-rise, or podium of high-rise buildings. The main deficiencies of the special scheme are reflected in three aspects.

\subsubsection{Lacking detail in the preparation of the basic treatment scheme}

Most of the floor-type scaffold are located on the relatively soft backfill soil; the compaction requirements of the backfill are vague, and the label, width, and drainage organization of the backfill concrete foundation are unclear ${ }^{[1]}$.

The compactness requirements shall be specified in the preparation and lifting of the scheme, and the plan details of each building or special parts and the section diagram of specific construction methods of the foundation shall be drawn. Only in this way can the construction be guided, the inspection be measured, the safety be guaranteed, and the measurement be based.

\subsubsection{Rough content in scheme preparation}

In order to avoid management inspection, the prepared scheme covers the small with the large and disregards the economy. In order to meet the requirements of national, industrial, and local government laws and regulations as well as the management inspection, the scheme preparation is represented by the working condition of the floor-type scaffold with higher height, and then it is stipulated that floor-type scaffold with a lower height shall implement the working condition scheme of the floor-type scaffold with a higher height. Although the plan is formulated and the plan itself is safe, the implementation is all empty talk. Due to the great difference in the actual investment in erection span, step distance, and foundation treatment of 10 meters, 20 meters and 30 meters floor-type scaffold, it is difficult for subcontractors and operators to implement this scheme. As a result, there is no scheme construction but an increase in potential safety hazards.

Therefore, in the preparation of the scheme, safety check calculation should be carried out one by one according to the required height of the scaffold erection with reasonable span and step distance. After comparative analysis, the conclusions that can be merged should be summarized, and detailed drawings should be provided to clarify specific individual buildings or areas, so as to implement the scheme and ensure safety ${ }^{[2]}$.

\subsubsection{Working conditions differ from the actual construction conditions}

It is mainly reflected in single multistorey public buildings and commercial podium buildings of group buildings. As the column spacing and storey height of the buildings are generally large, even if the wall connecting parts are set according to the "three steps and three spans" safety calculation software, the design dimensions of the column spacing and the storey height still do not meet the calculation conditions of the safety software. This is the common in-current design.

Therefore, after the safety check is passed, the prepared plan should be formulated according to the specific building or area and environmental conditions; the corresponding frame floor should be added with 
holding columns and upper floor beams, slabs, and other implementable parts. Measures such as adding wall fittings or ground bracings and drawing plans should be included to mark them.

\subsection{Cantilever scaffold}

The cantilever scaffold is an outer frame scheme widely used in high-rise buildings. The scheme basically meets the requirements of the height limit of the cantilever layer height of the frame body of 18 meters, and its safety has greatly improved. The main deficiencies of the special scheme are reflected in two aspects.

\subsubsection{Lacking detail in construction scheme drawings}

The safety checking calculation of the scheme can be guaranteed, but there is a lack of detailed construction scheme drawings. There are great differences in terms of the structural components among different types of architectural plane designs. The design layout of the fire evacuation ladder, elevator shaft, and pipe space in the building plane design layout is different, and the structural design of the column grid, column section size, shear wall, and corner on the structural plane is different. This has a great impact on the layout of steel beams supported by the cantilever scaffold ${ }^{[3]}$. It is not enough only to safely check the layout dimensions of the steel beam supported by the cantilever scaffold, the calculation parameters of the section, the length dimensions of the steel beam components, and the layout diagram.

Therefore, based on the parameters of safety calculation, it is necessary to supplement the layout drawing of cantilever scaffold supporting steel beam of specific building design type, clarify the plane size and section as well as the length size of steel beam components, and to be more detailed on the evacuation ladder, elevator shaft, pipe, corner, and other key parts. In this way, the construction preparation will be more sufficient, the construction guidance will be more specific, the assembly and disassembly will be more convenient, and the safety will be more guaranteed.

\subsubsection{Neglecting the systematicness of the scheme}

The influence of vertical transportation (tower crane and passengers-goods elevator) layout on the external frame is easily neglected. The outer scaffold mainly provides safety protection for high-altitude operation and operation platform for exterior facade decoration. The preparation and implementation of the outer frame scheme is easily neglected in the preparation of the outer frame before the vertical transportation layout. In this way, when installing vertical transportation equipment, the erected and closed frame needs to be disassembled and reinforced. At this time, not only will the investment be higher, but the stability of the outer frame will also be tested.

Therefore, the space requirements for the layout, installation, and use of vertical transportation equipment should be fully considered when preparing the special plan for outer scaffold; in addition, the treatment and strengthening measures within the scope of vertical transportation equipment should be specified on the elevation of outer scaffold erection, so as to minimize the impact on the safety and stability of the outer frame when installing vertical transportation equipment as well as to save investment ${ }^{[4]}$.

\subsection{Falsework}

The hazardous and super-hazardous schemes of falsework mainly include co-construction of house construction, apartment building, BCD business building, basement, and high-rise podiums formwork support scheme. The common features of these buildings are high storey height, large bay, deep beam, thick plate, primary and secondary beams, staggered arrangement of shear walls, and atrium in the building. 
At present, the safety checking calculation with the help of software is basically not a problem for the calculation. The deficiencies in the aforementioned housing construction scheme for falsework are discussed below.

\subsubsection{Neglecting the construction operation space}

The support frame does not leave 250-300 mm space for template installation, dismantling, and reinforcement on the outer surface of the beam, column, and shear wall, especially for deep beam and high fat column. The space distance is insufficient when workers install, reinforce, and dismantle the template. This requires that on the basis of safe working conditions, the parameters of the opposite rod should be adjusted reasonably, the need for appropriate operating space should be fully considered, and the parameters of safe working conditions as well as secondary safety hazards due to insufficient operating space should be avoided.

\subsubsection{Neglecting the safety check calculation for the side formwork of deep beam and high fat column}

During the safety check calculation of falsework, it is mainly for the frame body. It seems that the side template of deep beam and high fat column has no direct relationship with the support. In fact, if there is a weak point at the side mold of the tall formwork, it will cause overall harm to the safety of the support system. Therefore, when examining the drawing design and scheme, it is necessary to be strict and carry out scheme design as well as safety checking calculation for the side template of deep beam and high fat column to ensure a perfect overall scheme.

\subsubsection{Insufficient overall planning and selection as well as lacking local enhancement schemes}

Due to the characteristics of high building floor height, large spaces, deep beam, thick plate, and staggered arrangement of primary and secondary beams and shear walls, it is appropriate to carry out safety checking calculation on various support methods and layout parameters of primary and secondary beams as well as plate template supports on the same floor or construction section on the same floor, so that the vertical and horizontal parameters of primary and secondary beams and plates can be the same or meet the multiple levels on the basis of safety. For example, the plate vertical bar is $900 \times 900 \mathrm{~mm}$, the longitudinal spacing of the main beam vertical bar is $300 / 450 \mathrm{~mm}$, the secondary beam is $450 / 600 \mathrm{~mm}$, etc. In that way, the plate, main beam, and secondary beam vertical bars are in the multiple level in the longitudinal or transverse direction, the horizontal bars can be smoothly connected into a straight line in the multiple level spacing, and part vertical rods that do not have a single horizontal rod (longitudinal or transverse) connected to the whole within the multiple stage spacing can be reinforced with eight struts; Then, in the same layer or construction section, the frame can be connected as a whole to enhance the integrity and stability of the frame (as shown in Figure 1). 


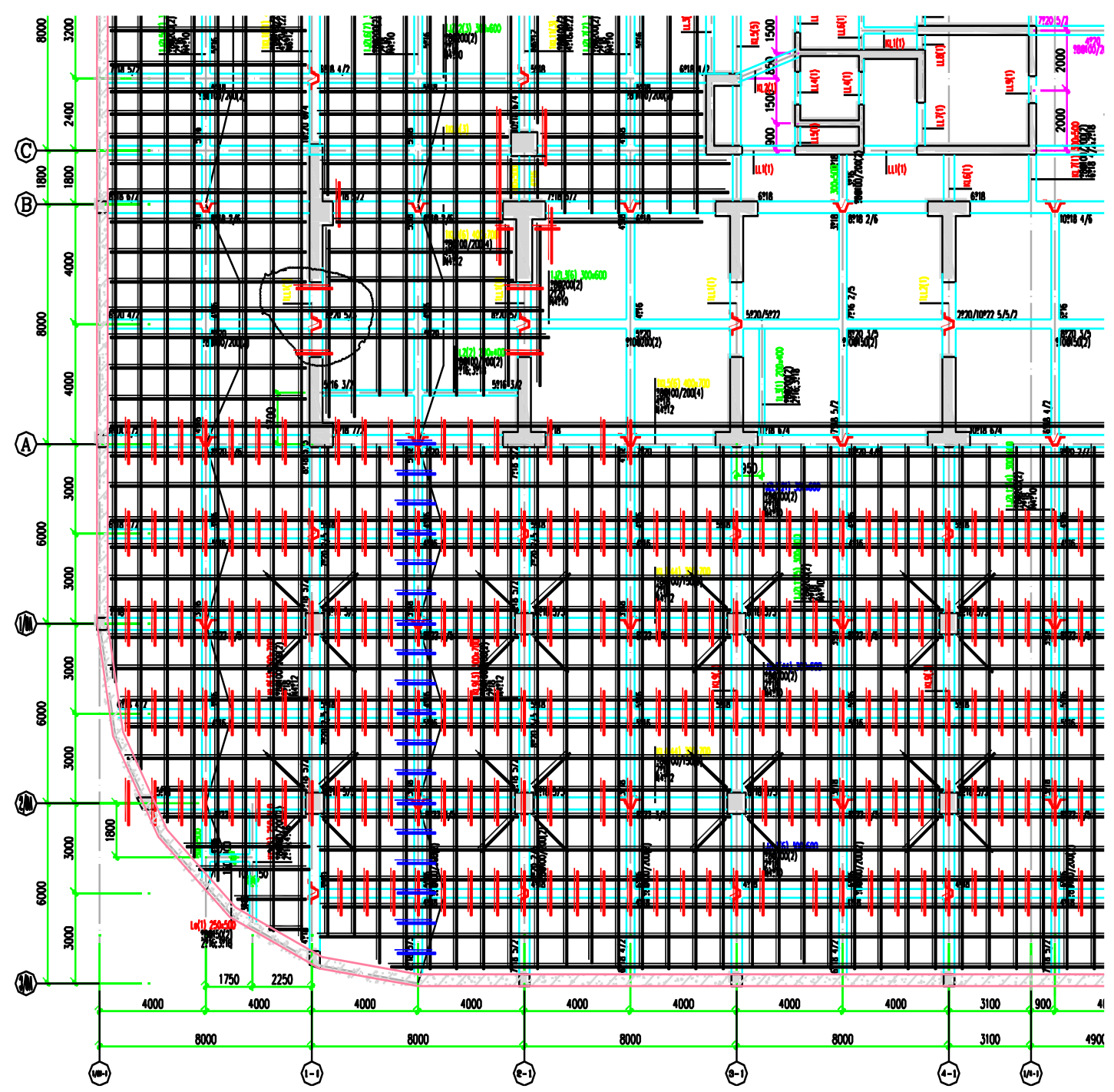

Figure 1. A construction drawing of the full framing layout adjusted according to safety check conditions (example)

The lack of local reinforcement scheme is mainly when high-rise buildings are constructed. The ground pump and distributing rod scheme is adopted for concrete pouring of high-rise buildings. The test shows that $2 \mathrm{kN}$ resistance increases at each $90^{\circ}$ elbow of the pump pipe, and its reaction force is transmitted to the falsework support system, causing damage to the stability of the falsework support ${ }^{[5]}$. Therefore, in the scheme, reinforcement measures should be taken for the bottom support frame of the material distributor boom, and reinforcement measures or reduction of resistance measures should be taken for the pump pipe at the horizontal and vertical turning parts.

\subsubsection{Emphasizing on the densification of upright tubes, while neglecting the adjustment of horizontal pole spacing in the design of beam height support scheme}

In this case, there is a high possibility of having too dense upright tubes, which would be difficult for construction operation, especially for the support of deep beams. The is due to the insufficient analysis of the software calculation results. In case of nonconformity, it is easy to simply judge that the bearing capacity of the upright tubes is insufficient, and the influence on the horizontal spacing of the high-formwork supports as well as the overall stability parameter i (radius of gyration) of the frame is not deep. At the same time, it is too inertial to think that the step distance of the upright pole is $1800 \mathrm{~mm}$. In fact, for the height of Chinese people, the step distance of $1650-1700 \mathrm{~mm}$ is more convenient to fasten bolts. Therefore, the 
results should be deeply analyzed when setting the scheme parameters, and a safe, economic, and convenient construction scheme should be given priority.

\section{Deficiency analysis and compilation improvement suggestions of special scheme for outer wall attached tower crane}

Tower cranes are the main mode of vertical transportation in the construction of high-rise and super-high structures in housing construction. There are several deficiencies in the preparation of the special scheme for outer wall attached tower cranes.

\subsection{Emphasizing on the coverage radius and demolition space requirements, while neglecting the impact on essential building components}

High-rise and super high-rise buildings basically have one or more basements, the red line of ground buildings is less than the outdoor side line of the basement, and there are many podium structures. In this way, the outer wall attached tower crane basically passes through the basement and podium structures. Due to the neglect of the impact of tower crane crossing on important building components, the main beams of basement and podium are often cut off during crossing, which has an adverse impact on the main structure in addition to creating potential safety hazards. Therefore, in the layout of tower cranes, the main structural members of the corresponding crossing area should be carefully checked and avoided; otherwise, BIM technology should be used for collision inspection.

3.2. Emphasizing on the space requirements for tower arm removal, while neglecting the requirements for safety and environmental conditions for wall connecting points removal

It is easy to arrange the connecting points at the smooth front gable area in the layout of the wall fittings. There are no protruding components, such as canopy, and it is far away from the opening for workers to enter and exit. When removing the connecting points, there is no safety platform at high places or environmental conditions for better erection of safety platform. Therefore, when setting wall connecting points, it is necessary to consider the safety requirements and environmental conditions for the next demolition or the conditions to facilitate the formulation of safety measures.

\subsection{Emphasizing on anti-collision in the final use state, while neglecting the use collision in the gradual lifting process}

The construction schedule is often different from the actual progress, which means that the lifting section and supporting wall formulated in the scheme are different from the actual progress requirements, so that the installation progress, sequence, as well as horizontal and vertical distance of adjacent tower cranes are different in the process of lifting section, or the independent height behind the supporting wall is greater than the limit height in technical documents.

Therefore, it is necessary to reasonably implement the plan and organization, dynamically monitor the construction process, as well as timely adjust the construction progress or increase the supporting wall measures.

\section{Deficiency analysis and compilation improvement suggestions of scheme for deep foundation pit with supporting structure}

Deep foundation pit construction is a divisional project with great impact of safety accidents, in which the deep foundation pit with supporting structure is more dangerous. 


\subsection{Unclear description of the features captured in the project profile}

In many schemes, the project overview of deep foundation pit is copied from the general design of construction organization, and the hydrogeological introduction is copied from the text description of geological exploration report. The general introduction of targeted deep foundation pit design scheme is less, and the geological and hydrological parameters required by the scheme are simple. The expression of the later lacks substantive bedding and support for the deep foundation pit. This is also a large program with little substantive content.

\subsection{Unclear key processes}

The scheme describes the construction of conventional construction support piles, mixing piles, and horizontal support beams in detail; however, the key processes of drainage, earthwork excavation, and horizontal support beam demolition are unclear.

\subsubsection{Deep well dewatering scheme}

In the deep well dewatering scheme, the hole forming process is more detailed, but there are few schemes and preventive measures on how to prevent blind wells, control water level, and backfilling the well hole. In drainage, the discharge direction of deep well drainage, the number of wells, the acceptance of peripheral municipal pipe network, the slope and section size of pit top drainage ditch, as well as the measures to prevent leakage are rarely involved.

\subsubsection{Earth excavation scheme}

In the earth excavation scheme, the dewatering effect, ramp construction, protection of horizontal support beam and the dewatering well pipe in the pit, layout description, and drawings of foundation pit monitoring points are insufficient, and some even omit the process of deep well dewatering directly in the process flow and schedule.

\subsubsection{Foundation pit with more than two layers of horizontal support beams}

For foundation pit with more than two layers of horizontal support beams, the key points of operation and control for the transformation of force transmission system before the removal of horizontal support beams are not clear.

\subsection{Weakening of traditional on-site inspection, dangerous situation judgment, and disposal scheme}

In terms of foundation pit monitoring, the scheme focuses on the monitoring scheme of technical means and weakens the traditional on-site inspection, dangerous situation judgment, and disposal scheme. According to practical experience, the traditional on-site inspection, dangerous situation judgment, and disposal scheme are more timely than the monitoring scheme of technical means, which can make comprehensive judgment and quick response better in combination with specific engineering site environment.

Due to the complexity, unpredictability, professionalism, technical content, and high construction practice requirements of deep foundation pit construction, in-depth study and practice summary are the main ways to improve. 


\section{Deficiency analysis and compilation improvement suggestions of special schemes for municipal bridges}

The special scheme for municipal bridges mainly discusses the special scheme for municipal concrete castin-situ box girder support. Its deficiency is similar to the deficiency of the formwork support scheme of high space, large span, as well as beam and slab in the room. The lack of pertinence and rationality leads to poor enforceability and economy, resulting in increased safety risk.

\subsection{Insufficient scheme refinement}

The construction load of cast-in-situ box girder has several section characteristics: near the support, outside the cantilever plate, standard section web and bridge plate, middle transverse beam, prestressed anchor, and tensioned serrated block. In scheme planning, the feature block is not fine; in addition, the multi-scheme comparison and selection are insufficient, leading to a waste of turnover materials or insufficient local safety degree. Moreover, the scheme is difficult to be implemented. Therefore, it is necessary to deeply study the drawings, accurately analyze the live load of the block, compare and select multiple schemes, as well as make overall planning.

\subsection{The preloading and measurement are not in strict accordance with the requirements of the specifications and regulations in actual construction}

The design of the elastic compression deformation of the formwork support material, the clearance of the rod assembly, the compression deformation of the foundation, and the suboptimal or missing foundation, especially the cast-in-situ box girder with high height and large load, greatly influence the safety. If there is sufficient estimation and calculation for the above situation during scheme preparation, there will be more instructive data, and corresponding remedial measures can be taken. Although the construction specifications and corresponding regulations have the requirements of preloading the formwork support on the construction site, the preloading and measurement are not in strict accordance with the requirements of the specifications and regulations in the actual construction. Therefore, it is advisable to seriously extract the above parameters required by the technology and calculate them as well as to take appropriate measures to avoid the above errors in the construction scheme, thus avoiding the adjustment of the frame body after preloading, the instability of extra-standard deformation, and extraction in the construction of concrete.

\section{Deficiency analysis and compilation improvement suggestions of Larsen steel sheet pile supporting scheme for municipal trenches}

The Larsen steel sheet pile supporting scheme has been adopted for many projects with support requirements in municipal trenches. From the approved schemes, there are some deficiencies.

\subsection{Failure of the self-gravity drainage trench in preparing specific measures according to the depth, soil, and hydrological conditions}

The gravity drainage trench flows with the help of hydraulic gradient, so the mileage length is long. Therefore, the trench depth shows a gradual trend with a continuous change in the depth. There are great differences in the soil and hydrological conditions. At the same time, there are also differences in the construction environment around the trench in the city.

Therefore, before preparing the plan, it is necessary to carefully study the drawings, geological exploration data, site survey, and historical data investigation. If necessary, supplementary geological survey and field environmental measurement should be conducted. During preparation, different sections 
should be divided according to different characteristic conditions; then, corresponding measures and schemes should be formulated.

\subsection{Lacking detail in the preparation of the scheme and weak guidance}

It is difficult to press the Larsen steel sheet pile into clay with a depth of 5 meters and a foundation bearing capacity of more than 20 tons in accordance with the working conditions of the scheme. On site, Larsen steel sheet pile is often excavated to an appropriate depth before construction, and then horizontal support is effectuated while excavating. Good retaining pressure can be obtained only when the soil wall is closely adhered to. In this way, a layer of earthwork is excavated first, and then pile pressing changes the scheme design condition. At this time, the preparation scheme would be predictable, so the filler at the back of Larsen steel sheet pile should be compacted before excavation and after the installation of horizontal support. In this way, it can avoid the sliding of the back wall and the destruction of the surrounding buildings under the influence of external environment when the trench earthwork continues to construct. There are also some super-deep trenches that use holes in the construction of Larsen steel sheet pile first, and there will also be loose adhesion or soft soil on the back wall between the lead hole and the Larsen steel sheet pile, so measures should be assumed in the preparation of the scheme. When the anchorage depth of Larsen steel sheet pile is insufficient, a plan should be formulated during preparation. If the number of layers of intermediate horizontal support or the foot support at the bottom of the trench increase, the construction section should be as short as possible, the process connection should be close, and the patrol inspection of the trench as well as the surrounding environment should be strengthened.

\section{Conclusion}

From the review of the scheme, this paper discusses several deficiencies and suggestions that need to be supplemented and improved based on personal experience. When preparing the scheme, "safety first" is affirmative; the rationality, operability, and economy of the scheme greatly affect its safety. At the same time, scheme preparation and construction operation support each other and have their own emphasis on safety control. Construction operation is much more complex for safety management compared to scheme preparation. Studies on this are still insufficient; therefore, it would be beneficial for other researchers or experts to contribute their experience to fortify this research.

\section{Disclosure statement}

The authors declare that there is no conflict of interest.

\section{References}

[1] Li K, Xu J, 2020, Analysis of Construction Case of High Support Formwork for Large and Dangerous Engineering. Mechanical and Electrical Information, 2020(9): 3.

[2] Zhou J, 2020, Construction Technology Scheme and Field Risk Control of Dangerous Engineering. Jiangxi Building Materials, 2020(5): 2.

[3] Wang Y, Wang X, 2020, Research on Construction Scheme Design and Review of Dangerous Construction. Building Technique Development, 2020(14): 2.

[4] Liu J, Ding Q, 2019, Key Points of Special Construction Plan Preparation of Tall Formwork. Engineering Quality, 37(2): 3. 
[5] Wang X, Wang Y, 2020, A Review of the Special Construction Scheme for Dangerous Projects. Real Estate Information of China.

Publisher's note

Bio-Byword Scientific Publishing remains neutral with regard to jurisdictional claims in published maps and institutional affiliations. 